\title{
A systematic review of faculty research repositories at higher education institutions
}

\author{
Patiswa Zibani \\ Durban University of Technology, Durban, South Africa \\ Mogiveny Rajkoomar \\ Department of Information Systems, Durban University of Technology, \\ Durban, South Africa, and \\ Nalindren Naicker \\ Durban University of Technology, Durban, South Africa
}

Faculty

research repositories

Received 29 April 2021 Revised 12 June 2021 Accepted 15 June 2021

\begin{abstract}
Purpose - This study aims to evaluate faculty research repositories used in higher education institutions, their different levels and functions with regard to research information management. This is revealed through the selected studies reviewed.

Design/methodology/approach - A systematic literature search of journal article studies on research repositories in higher education institutions was carried out on several databases, namely, Ebscohost, Emerald Insight, Science Direct, Sage, Google Scholar, SA e-Publications and citation databases such as Scopus and Web of Science. The systematic review was conducted in accordance with the preferred reporting items for systematic reviews and meta-analyses guidelines. The time frame for the analysis was 2015 to 2021.

Findings - The findings are presented on the motives for developing faculty research repositories the services provided and benefits derived from faculty research repositories and what is the utilization of faculty research repositories.

Originality/value - The results show that the development of research repositories at the faculty level enhances sharing, analysis, evaluation and preservation of scholarly research produced.
\end{abstract}

Keywords Repositories, Research data management, Research data, PRISMA, Cloud-based, Research platforms

Paper type Literature review

\section{Introduction}

The notion of establishing faculty repositories is slowly gaining traction as there are several benefits associated to such initiatives. This type of repository often contains non-ephemeral faculty-produced instructional materials, making it a useful resource for classroom teaching (Johnson, 2002). Concept graphics, visualizations, models, courses and videos are some of the

(C) Patiswa Zibani, Mogiveny Rajkoomar and Nalindren Naicker. Published by Emerald Publishing Limited. This article is published under the Creative Commons Attribution (CC BY 4.0) licence. Anyone may reproduce, distribute, translate and create derivative works of this article (for both commercial and non-commercial purposes), subject to full attribution to the original publication and authors. The full terms of this licence may be seen at http://creativecommons.org/licences/by/4.0/legalcode

Thanks to the Durban University of Technology for providing resources and funding for this research study.

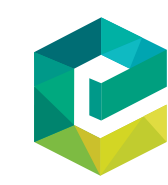

Digital Library Perspectives Vol. 38 No. 2, 2022 pp. $237-248$

Emerald Publishing Limited 2059-5816 
DLP

38,2

assets that can be found on course websites. While these resources are available elsewhere, the benefit for the repository is to have the resources curated in a central platform, thereby extending the appeal across a broader audience of research and teaching within the faculty. As observed by Tekian and Stapleton (2012), searching the Web for needed information or resources takes lots of time, so giving a faculty member a repository with relevant information could be a viable solution. A faculty repository is more than just teaching and learning digital platform, as it also stores scholarly research activity content. Through literature, we are observing the correlation between research activities and research performance measurement which can be linked to the existence of repositories and their functionalities to enable such assessments.

The measurement of research performance has become a rigorous activity in research-based higher education institutions (Kanngieser et al., 2014, pp. 302-318). This, in turn, has raised awareness to scholars and researchers into looking at enhancing the value and impact of every research paper they publish. Modern research repositories have incorporated current research information systems components and propose cutting edge, vast and interfaces that are userfriendly to researchers. Hence, they are key platforms for the management of research and online exposure of information about research outputs, current projects, research data, funding, research collaborations, research devices used, time on the research spent or the outcomes of the research. These platforms can also be used in the process of research data management. In addition, capturing information on the sources of data used in the research is an asset linked to publications (Jettena et al., 2019). As alluded by Wilkinson et al. (2016), the current research landscape requires data to be findable, accessible, interoperable and reusable (FAIR) in the long-term, as it has become the expectation within the academic community (universities, funding agencies, publishers). The implementation of FAIR principles will entrench robust management and administration of valuable digital resources that will be of benefit to higher education institutions. To enable full benefits of all the research and learning activities, that are vital to the ideal repository infrastructure used by institutions/units is a proper well-coordinated data management service that spans from the inception of the research through to collecting data, analyzing data, documentation, publishing, curing, preservation and management (Borgman et al., 2015).

Research repository platforms are broadly defined as the online "cloud"-based software modules that operate as portals for research efforts. The management of these software platforms are widely classified as nesting applications that add up content often provided by the "users." Research repository platforms also involve necessary connections with offline realms. In general, repositories provide network values that otherwise lead to deliberate shorttermism with strategic rationality. Digital repositories have features to ensure collaboration and communication among users. Higher Education Institutions must invest in technology resources and train staff to use the repository as an electronic repository to store ongoing faculty or departmental data related to research and learning activities (Kanngieser et al., 2014).

A systematic review of the extant literature of research repositories used at higher education institutions was attempted in this research paper. It also highlights the rationale behind the establishment of such repositories ranging from faculty learning activities, practice sharing program exercises, providing open, discoverable content, ensuring greater exposure to scholarly output, research data for sharing and re-use by students and staff in the faculty. As attributed by Sweeper and Ramsden (2020) a research repository is a critical component of establishing a new research plan and providing the incentive for fostering a research culture at a university. As universities work toward becoming leaders in research, showcasing research outputs, introducing it to a global audience becomes a priority.

As alluded by Armbruster and Romary (2010) the engagement in the digital realms have initiated the advancement of various technological repository solutions, such as institutional repositories, national repository systems, research repositories and subject based repositories. 
These different types of repository platforms can usually be set up within a higher education institution serving different purposes. These repository platforms can be as follows:

- Non-commercial and commercial subject-based repositories (single and associated) are typically established by a society and adopted by a community. The content is of inherent importance to scholars and this type of repository is characterized by spontaneous self-archiving. The ability to communicate research findings and views early in the form of working manuscripts and preprints provides authors with benefits such as the ability to claim primacy, evaluating the importance of a thought or finding prior to submission, refining a journal paper before submission, gaining recognition, attracting global attention, and so on (Armbruster and Romary, 2010). Faculty and departmental research repositories can be found within this range.

- Repositories for research are typically informed by funding for research mandates and often allow access and availability of research data to promote trustworthiness and transparency in the research process, thereby improving citations, and validate research conclusions through re-analyzing data to answer different research questions, as well as facilitate new discoveries (Elsevier, 2019; Ülikool, 2020). Faculty and departmental research repositories can be found within this range.

- National repository systems resemble federated systems, intended to capture research output by scholars to record scholarship, to support academic development in higher education.

- Institutional repositories comprise the various outputs of the institution as well as teaching and learning materials. Some institutional repositories have elements of current research information system that is useful for scholar profiles, funding, and publishing activities (Ülikool, 2020).

\section{Methodology}

The preferred reporting items for systematic reviews and meta-analyses (PRISMA) criteria were followed when conducting the systematic review (Moher et al., 2009). Sam, Naicker and Rajkoomar (2020) describe PRISMA as an evidence-based list of grouped items for preparing a report in meta-analyses and systematic reviews. PRISMA is a term used to refer to the combination of systematic review and meta-analysis. A systematic review is an audit of a planned questions that utilizes precise and unequivocal strategies to evaluate and examine data from the research studies that comprise the review (Sam et al., 2020).

\section{Inclusion criteria}

This study focused on a systematic review of faculty research repositories at higher education institutions. Three fundamental research questions were developed to span the breadth of this systematic review and obtain insights on early acceptance, development and benefits of faculties/departments repositories. The first question addressed the motivational aspects behind the development of faculty research repositories. The second question discussed the services provided and benefits of faculty research repositories. The third question discussed the utilization of faculty research repositories:

$R Q 1$. What are the motives for developing faculty research repositories?

$R Q 2$. What are the services provided and benefits derived from faculty research repositories?

$R Q 3$. What is the utilization of faculty research repositories? 
DLP

38,2

240

\section{Search approach}

This review paper adopted a systematic search approach to find relevant articles published in databases from January 2015 up to March 2021. Nine academic databases (Ebscohost, Emerald Insight, Science Direct, Sage, Google Scholar, SA e-Publications, SpringerLink Scopus and Web of Science) were searched. The systematic information retrieval applied the use of a combination of key search terms about the key ideas of the study as indicated in Table 1 . The included studies satisfied the following criteria: a faculty repository was defined as a central location for research, data and learning resources stored and managed within a higher education institution setting. It was also defined as a departmental research data repository platform that purely focuses on research data generated by the department or the faculty within a higher education institution setting. It was also defined as a research repository that deals with research and scholarly works representing a faculty within an institution of higher education. The steps taken included developing research questions, performing literature searches that were used to identify, screen and select relevant articles. Synthesis, analysis of articles and reporting of results was conducted.

The selected databases used in this review are commonly used in systematic literature reviews across disciplines. The search conducted yielded a retrieval of a total of 2,000 records. A total number of 1,925 duplicate records and articles were removed and the

\begin{tabular}{|c|c|c|}
\hline Database & Search strategy & $\begin{array}{l}\text { No. of } \\
\text { results }\end{array}$ \\
\hline $\begin{array}{l}\text { Ebscohost } \\
\text { Keywords } \\
\text { Year range: 2015-2021 }\end{array}$ & Faculty research repositories AND higher education institutions & 584 \\
\hline $\begin{array}{l}\text { Emerald Insight } \\
\text { Keywords } \\
\text { Year range: 2015-2021 }\end{array}$ & Departmental research data repositories AND higher education institutions & 1,000 \\
\hline $\begin{array}{l}\text { Science Direct } \\
\text { Keywords } \\
\text { Year range: 2015-2021 }\end{array}$ & Research platforms AND higher education institutions & 300 \\
\hline $\begin{array}{l}\text { Sage } \\
\text { Keywords } \\
\text { Year range: 2015-2021 }\end{array}$ & Research data management platforms AND higher education institutions & 5 \\
\hline $\begin{array}{l}\text { Google Scholar } \\
\text { Keywords } \\
\text { Year range: 2015-2021 }\end{array}$ & Research management platforms AND higher education institutions & 17 \\
\hline $\begin{array}{l}\text { SA e-Publications } \\
\text { (SABINET) } \\
\text { Keywords } \\
\text { Year range: } 2015-2021\end{array}$ & Research data platforms AND higher education institutions & 3 \\
\hline $\begin{array}{l}\text { SpringerLink } \\
\text { Keywords } \\
\text { Year range: 2015-2021 }\end{array}$ & Faculty research repositories AND higher education institutions & 5 \\
\hline $\begin{array}{l}\text { Web of Science } \\
\text { Keywords } \\
\text { Year range: 2015-2021 }\end{array}$ & Departmental research data repositories AND higher education institutions & 52 \\
\hline $\begin{array}{l}\text { Scopus } \\
\text { Keywords } \\
\text { Year range: 2015-2021 }\end{array}$ & Research platforms AND higher education institutions & 34 \\
\hline
\end{tabular}

Table 1.

Databases, search strategies and number of results 
remaining total of 75 full-text article records were screened further for relevance based on the inclusion criteria. Records that were found to be not relevant (40) were excluded and full-text articles (35) were assessed for eligibility. Further to that, full-text articles (24) that did not cover the complete review scope were removed and a qualitative synthesis was conducted on the 11 relevant articles (Figure 1).

\section{Findings}

The literature reviewed for this study is traced back from 2015 to 2021 and 11 articles were identified to be used. The articles were defined according to two categories conceptual and experimental. The conceptual category referred to articles that discussed the development or establishment of the faculty research repository, while experimental referred to project or prototype set up repositories geared for experimentation. Articles in the conceptual category discussed faculty repository adoption in different formats for different purposes and articles under the experimental category discussed experimental projects repositories.
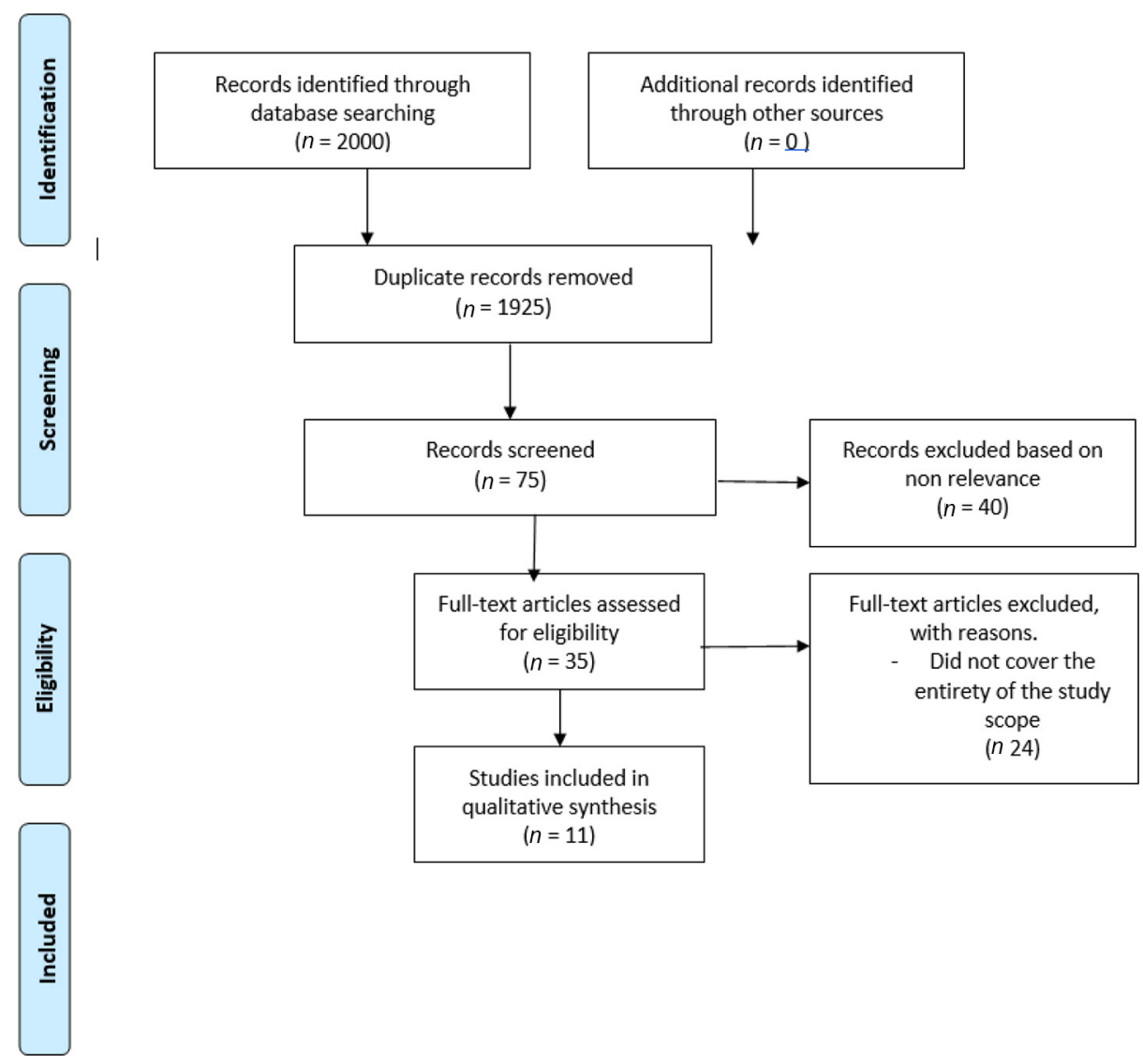

Figure 1.

A flowchart illustrating the process of selecting studies for the

PRISMA-guided systematic review 


\section{DLP}

38,2

\section{Analysis process}

The coding and analysis of articles were based on research questions. This was achieved using Microsoft Excel. Descriptive statistics in the form of tables, pie charts and graphs were used to present the review analysis. As indicated in Table 2 below, the spreadsheet recorded valuable and appropriate information about each article, such as the title, the author, the country where the article was published and the year of publication.

It is evident from the literature that there has not been much uptake in the development of faculty repositories from the social sciences disciplines. Most of the articles reviewed are science, technology, engineering and mathematics-based disciplines. The article written by Kem"enya et al. (2016, pp. 53-58) presented the development of the smart factory research repository platform as a relevant technical platform that reiterates the characteristics of a cyber-physical system and a non-traditional learning factory that promotes independent, immersive learning as part of a technical higher education programme. Another article written by $\mathrm{Xu}$ (2016) discussed an investigation to understand the faculty behavior in the use of a learning object (LO). This research was important for Wisc-Online, a repository of learning resources established by the Wisconsin Technical College System, to better understand the needs and usage patterns of the LOs. An article by Leng et al. (2016) discussed how Wawasan Open University Library initiated a research project for faculties using open access $(\mathrm{OA})$ repositories to host open educational resources. For this project, a Japanese open-source model called WEKO was used for faculties in collaboration with support services from the library. The review reveals that three-quarters of the articles

\begin{tabular}{|c|c|c|c|c|c|}
\hline ID & Author & Title & Year & Country & Type \\
\hline A1 & Heselden, M. et al. & $\begin{array}{l}\text { "Establishing an open access repository for } \\
\text { doctor of nursing practice projects" }\end{array}$ & 2019 & USA & Conceptual \\
\hline A2 & Jernigan, T.L et al. & $\begin{array}{l}\text { "The pediatric imaging, neurocognition, and } \\
\text { genetics (PING) data repository" }\end{array}$ & 2016 & USA & Experimental \\
\hline A3 & $\begin{array}{l}\text { Mi, X., Bernardy, } \\
\text { R., Schmidt, L. }\end{array}$ & $\begin{array}{l}\text { "Building an archaeological data repository: a } \\
\text { digital library and digital humanities } \\
\text { collaboration at the University of South Florida" }\end{array}$ & 2021 & USA & Conceptual \\
\hline A4 & Manu et al. & "Analysis of research data repositories in India" & 2018 & INDIA & Conceptual \\
\hline A5 & $\begin{array}{l}\text { Brouwer, D. du } \\
\text { Plessis, J.L. }\end{array}$ & $\begin{array}{l}\text { "Occupational hygiene-related research in South } \\
\text { Africa: development of a research repository" }\end{array}$ & 2016 & & Conceptual \\
\hline A6 & Tsabedze, V. & $\begin{array}{l}\text { "A framework for the management of E-records } \\
\text { in higher education institutions: a case study of } \\
\text { the Institute of Development Management, } \\
\text { Eswatini" }\end{array}$ & 2019 & SWAZILAND & Conceptual \\
\hline A7 & $\mathrm{Xu}, \mathrm{H}$. & $\begin{array}{l}\text { "Faculty use of a learning object repository in } \\
\text { higher education" }\end{array}$ & 2016 & USA & Conceptual \\
\hline A8 & O'Neill, B. et al. & $\begin{array}{l}\text { "Supporting nursing faculty with a digital } \\
\text { repository of simulation resources" }\end{array}$ & 2020 & AUSTRALIA & Experimental \\
\hline A9 & $\begin{array}{l}\text { Leng, C. B., Ali, K. } \\
\text { M. and Hoo, C. E. }\end{array}$ & $\begin{array}{l}\text { "Open access repositories on open educational } \\
\text { resources: feasibility of adopting the Japanese } \\
\text { model for academic libraries" }\end{array}$ & 2016 & MALAYSIA & Experimental \\
\hline $\mathrm{A} 10$ & Kem'eny, Z.et al. & $\begin{array}{l}\text { "The MTA SZTAKI smart factory: platform for } \\
\text { research and project-oriented skill development } \\
\text { in higher education" }\end{array}$ & 2016 & HUNGARY & Experimental \\
\hline A11 & $\begin{array}{l}\text { Tamizhchelvan, M. } \\
\text { and Anbalagan, M. }\end{array}$ & $\begin{array}{l}\text { "Indian Research Information Network System } \\
\text { (IRINS): an analysis of faculty profiles of the } \\
\text { Gandhigram Rural Institute - Deeded to be } \\
\text { University" }\end{array}$ & 2020 & INDIA & Conceptual \\
\hline
\end{tabular}

\section{Table 2.}

List of the articles that were included in the systematic review of faculty research repositories in higher education institutions University" 
selected $(77 \%)$ are categorized as conceptual and the development of the repository is used as project inception or model. This can be alluded to the fact repositories are platforms developed to create, store, publish and use for learning and research by libraries, as opposed to faculties and departments (Allison-Cassin and Scott, 2018).

It is evident from literature that there has not been much uptake on the development of faculty repositories from the social sciences disciplines. It is between 2018 and 2021 where literature reveals a full take in the six publications that extensively discussed research repositories with relevance to faculties/departments in higher education institutions. The geographical distribution of the articles of an article reviewed reveals countries such as the USA (37\%), India (18\%), Australia (9\%), Hungary, Malaysia, South Africa and Swaziland $(9 \%)$ (Figure 2).
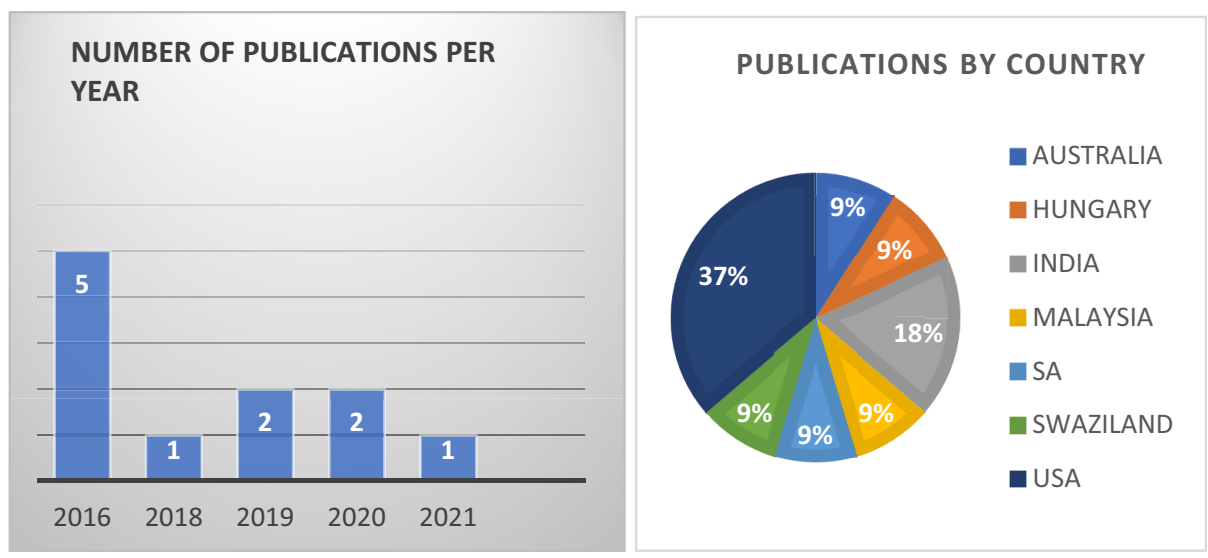

\section{Faculty research repositories}

This section covers the results of the systematic review based on the research questions that were created.

RQ1: What are the motives for developing faculty research repositories in the current literature? Higher education institutions have adopted institutional repositories that are mostly administered by their libraries. When current library systems are functioning successfully, library directors may be interested in learning about the reasons for the development of research repositories by universities or departments. Therefore, the objective for the first research question was to establish the motive behind the development of faculty research repositories. The table below lists the motivations and ranks them according to the coding of 11 articles examined for this study (Table 3 ).

\begin{tabular}{llcc}
\hline Article (A) ID & Motive & Count & (\%) \\
\hline A1, A2, A3, A4, A7, A8, A9, A10, A11 & Sharing students' projects, access, discoverability & 9 & 81 \\
A2, A4, A6, A11, A8, A9 & Archive and curation & 6 & 54 \\
A1, A2, A3, A4 & Collaboration and enhanced discoverability to & 4 & 36 \\
A1, A3, A4 & rare content collections & 3 & 27 \\
\hline
\end{tabular}

Table 3.

Motivations and ranking according to articles reviewed
Selected articles by publication year and country 
DLP

38,2

The review revealed the dominating factors ranking highest behind the motive for developing faculty research repositories to be sharing, access and discoverability of unique collections, projects and LOs that faculties tend to have that are informed by their programs. As noted by Henderson (2008), Matkin (2002) and University System of Georgia (2015) a repository allows information to be reused and shared, lowering the cost and duplication of work in the creation of instructional materials.

The second prevalent motive for developing faculty research repositories was archiving and curation. The gradual paradigm shift that is embraced by the scholarly community recognizes the value of curriculum learning content and all forms of research outputs. The curation and archiving motives are not new but have gained momentum as scholars became aware of the advancements in scientific research and the growth in attention (Fienberg et al., 1985; Glaeser, 1990; Yoon, 2015). The demand for long-term research preservation, access and re-use has grown, especially in data-intensive science, which is characterized by escalating data deluge issues. (Kahn et al., 2014; Kim et al., 2013, p. 67; Schumacher and Vande Creek, 2015, p. 97; Walters and Skinner, 2011). The least identified motive was the ease of use and consistency of these platforms. There is no surprise to that as repository system platforms are designed with built-in elements that support ease of use and consistency. The built-in design and architecture of research repositories aid in the understanding that descriptive metadata indicating resource, researcher and research process information is supplemented with OA/open data (OD) designs and strategies known as linked OD and semantic Web architecture. This is best addressed by the University of Central Florida Libraries (Deng, 2018) and a plethora of other concerns listed below:

- The internet, digital research repositories and knowledge management systems - also known as controlled thesauri/subject headings and name identifiers.

- Scanning the environment for authority control in repositories.

- Disambiguation and identification of names.

- Using author information, subject and keywords to create engaging user interfaces (UIs).

- Text analysis, controlled vocabularies and Web-based metadata.

- OA and proprietary.

- Authority control; identity management and discovery.

RQ2: What are the services provided and benefits derived from faculty research repositories? The advent of OA has given rise to new inexpensive ways of managing research activities, scholarly publishing and communication. That has resulted in universities investing in the development repository networks to speed up the availability of information (Shearer et al., 2015). Faculty are experimenting and extending research repositories to faculty or departmental levels to achieve numerous benefits such as enriching and exhibiting their collections, as evidenced by the sample of articles included in this review. Similarly, the ability of a research repository to provide open material provides researchers with a database to record and store data at various stages of a project, then maintain it for the long term and give interconnections between 
projects documented (Mi et al., 2021). What began as a proposal from the American Association of Colleges of Nursing in 2015 to archive doctoral nursing projects (DNP) in a digital repository soon found additional benefits beyond compliance, according to an article by Heselden et al. (2019). The DNP graduates were given the opportunity to display their work in a public forum, providing the faculty with a platform to highlight the breadth of nursing research performed by students and further promoting nursing scholarship. As mentioned by Brouwer and du Plessis (2016) in the article reviewed, one of the benefits that can be attained is the ability to provide background information to the discussions about a specific discipline or research agenda. This could be information about current research topics that are being addressed and the focus research groups.

\section{RQ3: What is the utilization of faculty research repositories?}

This topic was posed to learn more about how research repositories are used in faculty operations. Table 4 shows the many, yet related, tendencies that emerged from the articles.

The identified trends from the review range from building an attractive Web presence that is easily accessible and promotes the faculties' repository. As most faculty members learn about their repositories' services through channels including internet searching, peer recommendation, university and college training and promotion events, advertising the repositories becomes an effective approach to recruit faculty users. Another contributing factor to utilization is the ease to access and use of the platform. As alluded by Jernigan et al. (2016), faculty repositories are organized and structured, therefore, eliminate the responsibility of reinventing and creating standards. The articles sampled also revealed that utilization was also pushed by the fact that repositories provide consistency in their applications. In the article by Jernigan et al. (2016) a participant was noted saying, "Course coordinators in the nursing school agreed they had faced challenges in the past where they had planned multicampus clinical simulation exercises for students only to find the resources were not equally accessible across all campuses, and this created barriers to their subsequent use." Other articles reported utilization to adopt research data management strategies within specific disciplines for emulation purposes and collaboration opportunities.

\begin{tabular}{|c|c|c|c|c|}
\hline Article (A) ID & Utilization patterns & Count & $(\%)$ & \\
\hline $\mathrm{A} 1, \mathrm{~A} 2, \mathrm{~A} 3, \mathrm{~A} 4, \mathrm{~A} 7, \mathrm{~A} 8, \mathrm{~A} 9, \mathrm{~A} 10, \mathrm{~A} 11$ & Course content enrichment & 9 & 81 & \\
\hline $\mathrm{A} 1, \mathrm{~A} 2, \mathrm{~A} 3, \mathrm{~A} 4, \mathrm{~A} 7, \mathrm{~A} 8, \mathrm{~A} 9, \mathrm{~A} 10, \mathrm{~A} 11$ & $\begin{array}{l}\text { Easy to access and use } \\
\text { Consistency }\end{array}$ & 9 & 81 & \\
\hline $\mathrm{A} 1, \mathrm{~A} 2, \mathrm{~A} 3, \mathrm{~A} 4, \mathrm{~A} 7, \mathrm{~A} 8, \mathrm{~A} 9$ & $\begin{array}{l}\text { Download and combine the LO to my course } \\
\text { directly without modification }\end{array}$ & 7 & 63 & \\
\hline $\begin{array}{l}\mathrm{A} 1, \mathrm{~A} 2, \mathrm{~A} 3 \\
\mathrm{~A} 7, \mathrm{~A} 8, \mathrm{~A} 9\end{array}$ & See how others create LOs & 6 & 54 & Table 4. \\
\hline $\mathrm{A} 3, \mathrm{~A} 4, \mathrm{~A} 5, \mathrm{~A} 9, \mathrm{~A} 10, \mathrm{~A} 11$ & Research data management & 6 & 54 & Utilization patterns \\
\hline $\mathrm{A} 3, \mathrm{~A} 4, \mathrm{~A} 5, \mathrm{~A} 9, \mathrm{~A} 10, \mathrm{~A} 11$ & Collaborate with other researchers & 6 & 54 & for faculty \\
\hline $\mathrm{A} 3, \mathrm{~A} 4, \mathrm{~A} 5, \mathrm{~A} 9, \mathrm{~A} 10, \mathrm{~A} 11$ & See how others create data management plans & 6 & 54 & repositories \\
\hline
\end{tabular}


DLP

38,2

\section{Conclusion}

A systematic evaluation of faculty research repositories at higher education institutions was conducted to obtain insight into the development, motives, benefits and uptake within faculties/departments in this paper. Faculty are embracing the concept of faculty research repositories for a variety of reasons, including the creation of open and reusable knowledgebase of structured data collections, consistency, ease of use, easy management and storage of research data, learning projects, scholarly outputs and collaboration platforms with peers in the same discipline, according to the study. The overall impression from the review was that the notion of a faculty repository was well-received, with early adopters indicating that it was fully used as it was seen to fit the needs of the faculty with simple content that addressed a variety of levels of interest and competence. Furthermore, the repository ability to enhance the global visibility of its collection with ease in access, discoverability and sharing are dominating motivations revealed in this review paper. While repositories benefit to faculties include showcasing unique, rare and marginalized collections, making repository operations and workflows is a challenge and calls commitment and investment to ensure that repositories remain useful and relevant to faculty members and specific disciplines served. The future sustainability of faculty repositories will be contingent upon faculty research administrators' willingness to taking full ownership of these platforms as custodians of the content found. Ownership involves a desire to accept and invest in the repository as a resource platform rather than as a means of operation.

\section{References}

Allison-Cassin, S. and Scott, D. (2018), "Wikidata: a platform for your library's linked open data", Code4Lib Journal, No. 40, available at: https://journal.code4lib.org/articles/13424.V (accessed on 15 April 2021).

Armbruster, C. and Romary, L. (2010), "Comparing repository types: challenges and barriers for subject-based repositories, research repositories, national repository systems and institutional repositories in serving scholarly communication", International Journal of Digital Library Systems, Vol. 1 No. 4, pp. 62-63.

Brouwer, D. and Du Plessis, J.L. (2016), "Occupational hygiene-related research in South Africa: development of a research repository", Occupational Health Southern Africa, Vol. 22 No. 4.

Deng, S. (2018), "Expanding the metadata librarian horizon: reflections on the metadata practices in the web and digital repositories", presented at the 2018 ALA Midwinter Meeting.

Elsevier (2019), "Sharing research data", available at: www.elsevier.com/authors/author-services/ research-data

Fienberg, S.E., Martin, M.E. and Straf, M.L. (1985), Sharing Research Data, Washington, DC, National Academy Press.

Glaeser, P.S. (1990), Scientific and Technical Data in a New Era, New York, NY, Hemisphere Publishing Corporation.

Henderson, S. (2008), "The OnCoRe blueprint: the art and science of repository creation", Proceedings of 8th Annual MERLOT International Conference, Minneapolis, p. 15.

Jernigan, T.L., Brown, T.T., Hagler Jr, D.J., Akshoomoff, N., Bartsch, H., Newman, E., Thompson, W.K., Bloss, C.S., Murray, S.S., Schork, N. and Kennedy, D.N. (2016), "The pediatric imaging, neurocognition, and genetics (PING) data repository", Neuroimage, Vol. 124, pp. 1149-1154.

Jettena, M., Simons, E. and Rijnders, J. (2019), “The role of CRIS's in the research life cycle. A case study on implementing a FAIR RDM policy at radboud university, Netherlands", Procedia Computer Science, Vol. 146 No. 2019, pp. 156-165. 
Johnson, R.K. (2002), "Institutional repositories: partnering with faculty to enhance scholarly communication”, D-Lib Magazine, Vol. 8 No. 11.

Kahn, M., Higgs, R., Davidson, J. and Jones, S. (2014), "Research data management in South Africa: how we shape up", Australian Academic and Research Libraries, Vol. 45 No. 4, pp. 296-308.

Kanngieser, A., Neilson, B. and Rossiter, N. (2014), "What is a research platform? Mapping methods, mobilities and subjectivities", Media, Culture and Society, Vol. 36 No. 3, pp. 302-318.

Kem“Enya, Z., Richard, Beregia, J.R., Erdos, G. and Nacsa, J. (2016), "The MTA SZTAKI smart factory: platform for research and project-oriented skill development in higher education", Procedia CIRP, Vol. 54, pp. 53-58.

Kim, J., Warga, E. and Moen, W. (2013), “Competencies required for digital curation: an analysis of job advertisements", International Journal of Digital Curation, Vol. 8 No. 1, pp. 66-83.

Leng, C.B., Ali, K.M. and Hoo, C.E. (2016), "Open access repositories on open educational resources: feasibility of adopting the Japanese model for academic libraries", Asian Association of Open Universities Journal, Vol. 11 No. 1, pp. 35-49.

Matkin, G.W. (2002), "Learning object repositories: problems and promise", available at: www.hewlett. org/uploads/files/LearningObjectRepositories

Mi, X., Bernardy, R. and Schmidt, L. (2021), "Building an archaeological data repository: a digital library and digital humanities collaboration at the university of South Florida", International Journal on Digital Libraries, Vol. 22 No. 1, pp. 135-145.

Moher, D., Liberati, A., Tetzlaff, J., Altman, D.G. and Group, P. (2009), "Preferred reporting items for systematic reviews and meta-analyses: the prisma statement", Annals of Internal Medicine, Vol. 151 No. 4, pp. 264-269.

Sam, Naicker and Rajkoomar (2020), "Meta-Analysis of artificial intelligence works in ubiquitous learning environments and technologies", International Journal of Advanced Computer Science and Applications, Vol. 11 No. 9.

Schumacher, J. and Vande Creek, D. (2015), "Intellectual capital at risk: data management practices and data loss by faculty members at five American universities", International Journal of Digital Curation, Vol. 10 No. 2, pp. 96-109, doi: 10.2218/ijdc.v10i2.32.

Shearer, K., Haigh, S. and Whitehead, M. (2015), "Supporting Canadian innovation through shared expertise and stewardship of research data", Paper Presented on the 81st IFLA General Conference and Assembly, Cape Town, South Africa, pp. 15-21.

Sweeper, D. and Ramsden, K. (2020), "Establishing and promoting an institutional repository and research information management system”, Library Hi Tech News, Vol. 37 No. 7, pp. 9-12.

Tartu Ülikool (2020), "Data repositories”, available at: https://sisu.ut.ee/rdm_course1/data-repositories (accessed on 11 April 2021).

Tekian, A. and Stapleton, G. (2012), "Online resources for healthcare SIMULATION", The Clinical Teacher, Vol. 9 No. 6, pp. 417-419.

University System of Georgia (2015), "Learning object repository", available at: https://wiki.ucop.edu/ download/attachments/3737/lor05_17_06

Walters, T. and Skinner, K. (2011), "New roles for new times: digital curation for preservation", Washington, DC, Association of Research Libraries, available at: http://files.eric.ed.gov/fulltext/ED527702.pdf

Wilkinson, M.D, et al. (2016),. "The FAIR guiding principles for scientific data management and stewardship. Scientific data", Article number: 160018 (2016), available at: www.nature.com/articles/sdata201618

$\mathrm{Xu}, \mathrm{H}$. (2016), "Faculty use of a learning object repository in higher education", VINE Journal of Information and Knowledge Management Systems, Vol. 46 No. 4, pp. 469-478.

Yoon, A. (2015), "Data reuse and users' trust judgments: toward trusted data curation", Doctoral dissertation, The University of North Carolina at Chapel Hill): USA. 
DLP

38,2

\section{Further reading}

Manu, T.R., Viral, A., Madesh, G., Shashikumara, A.A., Panna, C. and Prasanna, K. (2018), “Analysis of research data repositories in India”, Knowledge Organisation in Academic Libraries.

O'Neill, B., et al., (2020), "Supporting nursing faculty with a digital repository of simulation resources", Teaching and Learning in Nursing, Vol. 15 No. 3, pp. 175-180.

Tsabedze, V. (2019), "A framework for the management of E-records in higher education institutions: a case study of the institute of development management", Mousaion: South African Journal of Information Studies", Vol. 37 No. 3.

\section{Corresponding author}

Nalindren Naicker can be contacted at: nalindrenn@dut.ac.za

For instructions on how to order reprints of this article, please visit our website: www.emeraldgrouppublishing.com/licensing/reprints.htm

Or contact us for further details: permissions@emeraldinsight.com 